\title{
OP41
}

\section{DISCOMFORT GLARE CUT-OFF VALUES FROM FIELD AND LABORATORY STUDIES}

\author{
Clotilde Pierson et al.
}

DOI 10.25039/x46.2019.OP41

from

CIE x046:2019

\section{Proceedings}

of the

29th CIE SESSION

Washington D.C., USA, June 14 - 22, 2019

(DOI 10.25039/x46.2019)

The paper has been presented at the 29th CIE Session, Washington D.C., USA, June 14-22, 2019. It has not been peer-reviewed by CIE.

\section{(C) CIE 2019}

All rights reserved. Unless otherwise specified, no part of this publication may be reproduced or utilized in any form or by any means, electronic or mechanical, including photocopying and microfilm, without permission in writing from CIE Central Bureau at the address below. Any mention of organizations or products does not imply endorsement by the CIE.

This paper is made available open access for individual use. However, in all other cases all rights are reserved unless explicit permission is sought from and given by the CIE.

CIE Central Bureau

Babenbergerstrasse 9

A-1010 Vienna

Austria

Tel.: +43 17143187

e-mail: ciecb@cie.co.at

www.cie.co.at 


\title{
DISCOMFORT GLARE CUT-OFF VALUES FROM FIELD AND LABORATORY STUDIES
}

\author{
Pierson, C. ${ }^{1}$, Sarey Khanie, M. ${ }^{2}$, Bodart, M. ${ }^{1}$, Wienold, J. ${ }^{3}$ \\ 1 Université catholique de Louvain, Louvain-la-Neuve, BELGIUM, ${ }^{2}$ Technical University of \\ Denmark, Kongens Lyngby, DENMARK, ${ }^{3}$ École Polytechnique Fédérale de Lausanne, \\ Lausanne, SWITZERLAND \\ clotilde.pierson@uclouvain.be
}

DOI $10.25039 / \times 46.2019 .0 P 41$

\begin{abstract}
For the application of discomfort glare metrics, a categorisation is used, dividing the metric scale into categories of perception. These categories are separated by borderline values, or so-called cut-off values. Recent literature shows that these cut-off values are lower when they are derived from field study data than those derived from laboratory study data. To investigate this further, the data from one field study and two laboratory studies was used to derive and compare cut-off values corresponding to three borderlines. The results show that the field study cut-off values were systematically lower than the laboratory study ones, implying that discomfort glare is reported at lower stimulus magnitudes in the field. Although further research is required on that topic, several hypotheses are discussed in order to explain the gap between cut-off values derived from field data and cut-off values derived from laboratory data. Recommendations for future studies are also provided.
\end{abstract}

Keywords: Daylight, Discomfort glare, Cut-off value, Laboratory study, Field study

\section{Introduction}

Developing reliable and accurate methods to evaluate visual discomfort remains a crucial step to move towards optimal daylighting design in buildings. To date, over twenty daylight discomfort glare models have been developed, mainly from laboratory studies using office-like settings with daylight, e.g. (Chauvel, 1982, Wienold, 2006, Fisekis, 2003, Yamin Garretón, 2018), or with simulated daylight, e.g. (Hopkinson, 1963, Tokura, 1996).

These models are based on several physical quantities of the visual scene, such as the glare source luminance, the background luminance, the solid angle and the position index of the glare source, or the vertical illuminance (Pierson, 2018). By inputting these quantities into a discomfort glare model, an estimation of the magnitude of discomfort glare in that visual scene is generated on a numeric scale. For each discomfort glare model and their corresponding scale, cut-off values corresponding to the borderlines between different magnitudes of discomfort glare are provided. For instance, the cut-off values for the Daylight Glare Probability (DGP) index, of which the scale ranges from 0 to 1 , are defined (Reinhart, 2011) as:

- $0.35=$ Borderline between Imperceptible and Noticeable glare (BIN)

- $0.40=$ Borderline between Noticeable and Disturbing glare (BND)

- $0.45=$ Borderline between Disturbing and Intolerable glare (BDI)

Through field studies, researchers have attempted to validate these daylight discomfort glare models and their corresponding cut-off values. Their results indicate that the models generally underestimate discomfort glare that is perceived by occupants in real office environments (Hirning, 2014, Mangkuto, 2017). As an example, the DGP value representative of $50 \%$ of participants being disturbed by discomfort glare in field studies was evaluated as 0.2 (Hirning, 2014) or 0.24 (Mangkuto, 2017). However, from a meta-analysis study combining results from seven laboratory studies (Wienold, 2019), the DGP value derived as the cut-off value between noticeable and disturbing glare was 0.38 . Although the cut-off values from the laboratory and field studies were not derived in the same manner, the gap between the values is considerable as it averages around 0.16 . 
The aim of this study is to investigate the hypothesis that the cut-off values derived from laboratory studies are higher than those derived from field studies, suggesting that subjects tolerate higher levels of discomfort glare in office-like laboratory cells than in real offices. To achieve this objective, the cut-off values of three common daylight discomfort glare models derived in the same manner and using data from similar studies - though one is a field study, and the two other ones are laboratory studies - are compared. The results provide the quantification of the gap that should be expected between the cut-off values from laboratory and field studies. Finally, the conclusion draws assumptions on the reasons for this gap.

\section{Methodology}

To compare discomfort glare perceptions from daylight between field and laboratory studies, cut-off values of daylight discomfort glare metrics were derived for three borderlines, from three studies amongst which two are laboratory studies, and one is a field study. The discomfort glare metrics, the glare scale, the cut-off values derivation method, and the studies used for the comparison are described in detail in this section.

\subsection{Daylight Discomfort Glare Metrics}

Three daylight discomfort glare metrics were chosen to be representative of the three types of metrics, i.e. the metrics that consider contrast glare, those that consider saturation glare, and those that consider both. Saturation glare is due to a too large amount of light reaching the observer's eyes, whereas contrast glare is due to too strong a contrast between the viewing direction and a bright spot in the field of view (Pierson, 2018).

For this study, the best metric of each type according to a recent cross-validation study (Wienold, 2019) was selected. The DGP (Equation 1) developed in (Wienold, 2006) was chosen as the contrast and saturation glare metric; the vertical illuminance $\left(E_{v}\right)$ proposed in (Velds, 2000 ) as the saturation glare metric; and the CIE Glare Index (CGI) (Equation 2) developed in (Einhorn, 1979) as the contrast glare metric.

$$
\begin{aligned}
& D G P=5.87 \cdot 10^{-5} \cdot E_{v}+9.18 \cdot 10^{-2} \cdot \log \left(1+\sum_{i=1}^{n} \frac{L_{s, i}^{2} \cdot \omega_{s, i}}{E_{v} \cdot 87 \cdot P_{i}^{2}}\right)+0.16 \\
& C G I=8 \cdot \log 2 \cdot \frac{\left(1+\frac{E_{\text {dir }}}{500}\right)}{E_{\text {dir }}+E_{\text {ind }}} \cdot \sum_{i=1}^{n} \frac{L_{s, i}^{2} \omega_{S, i}}{P_{i}^{2}}
\end{aligned}
$$

where

$E_{v} \quad$ is the illuminance in a vertical plane at eye level [lux];

$L_{s, i} \quad$ is the mean luminance of the glare source $\left[\mathrm{cd} / \mathrm{m}^{2}\right]$;

$\omega_{s, i}$ is the solid angle subtended by the glare source [sr];

$P_{i} \quad$ is the position index [-];

$E_{d i r} \quad$ is the direct Illuminance (illuminance only by the glare sources) [lux];

$E_{\text {ind }}$ is the indirect Illuminance (illuminance only by the background) [lux].

The cut-off values were derived for each of these three daylight discomfort glare metrics.

\subsection{Discomfort Glare Scale}

Since discomfort glare is a subjective phenomenon, it calls for methods of investigation involving subjective judgements (Osterhaus, 2004). These judgements are usually made on discomfort glare rating scales. Nowadays, there exist many different discomfort glare rating scales. In daylight glare research, the most common is a 4-point scale introduced by (Osterhaus, 1992). This scale goes from Imperceptible glare to Noticeable, Disturbing, and Intolerable glare, and has been used frequently in recent discomfort glare studies (Kuhn, 2013, Wienold, 2006, Konstantzos, 2016, Yamin Garretón, 2014, Painter, 2009, Erell, 2014).

Since this 4-point scale was adopted to collect the data in the three studies, the cut-off values will be derived for the three borderlines of the scale, namely the Borderline between Imperceptible and Noticeable glare (BIN), the Borderline between Noticeable and Disturbing glare (BND), and the Borderline between Disturbing and Intolerable glare (BDI). 


\subsection{Laboratory and Field Studies}

The data used to derive the cut-off values were collected both in a laboratory setting and in real offices, in order to compare the derived cut-off values between the two environments. On the one hand, data from two laboratory studies having a similar protocol and conducted in the same laboratory cell in Freiburg (Germany) were used.

The first laboratory study was conducted between 2008 and 2011 with 49 participants assessing a total of 196 visual scenes (Moosmann, 2012). The study was performed under clear sky conditions, in an office-like laboratory cell with a window and two shading devices (white Venetian blinds or fabric shadings). Lighting measurements, i.e. luminance maps, were collected simultaneously to the participant's subjective assessment, with the equipment located besides the participant's head (Figure 1 left). Before the start of the session, the participants did a first glare assessment as training under artificial lighting. During a session, discomfort glare assessments were made on the 4-point glare rating scale through a questionnaire on paper and preceded by a visual task. For this study, only the first daylit scene assessed by each participant is used, to achieve a between-subject experiment.

The second laboratory study was conducted in 2013 in the same laboratory cell with 97 participants (Sarey Khanie, 2017). No shading devices were used, but both clear and overcast skies occurred during the experiment, introducing five different daylit conditions to the scene depending on the presence and amount of direct sun patches or sun in the field of view. A participant only evaluated one of the five types of scene. Luminance maps were collected every 30 seconds during the entire session, with the equipment located above the participant's head (Figure 1 middle). Although each participant made several subjective assessments on the 4point glare rating scale for the same scene, i.e. one after each phase (4) of each office task (2), only the assessment made after the typing phase of the computer-based task was used for the purpose of this study.

On the other hand, data from one field study conducted in Lausanne (Switzerland) under clear sky conditions in summer 2018 was used. The protocol is the same as the one published in (Pierson, 2017). In total, 111 participants evaluated the visual scene of their own office desk located next to a South-, East-, or West-oriented window. The participants did a first discomfort glare evaluation, preceded by a visual task, in the original lighting conditions as training. The shading devices were then fully opened, and after an adaptation time, the participants did a second visual task and subjective assessment on the 4-point scale in a questionnaire on their computer screen. Luminance maps were collected directly after the subjective assessment, at the same location as the participant's head (Figure 1 right).
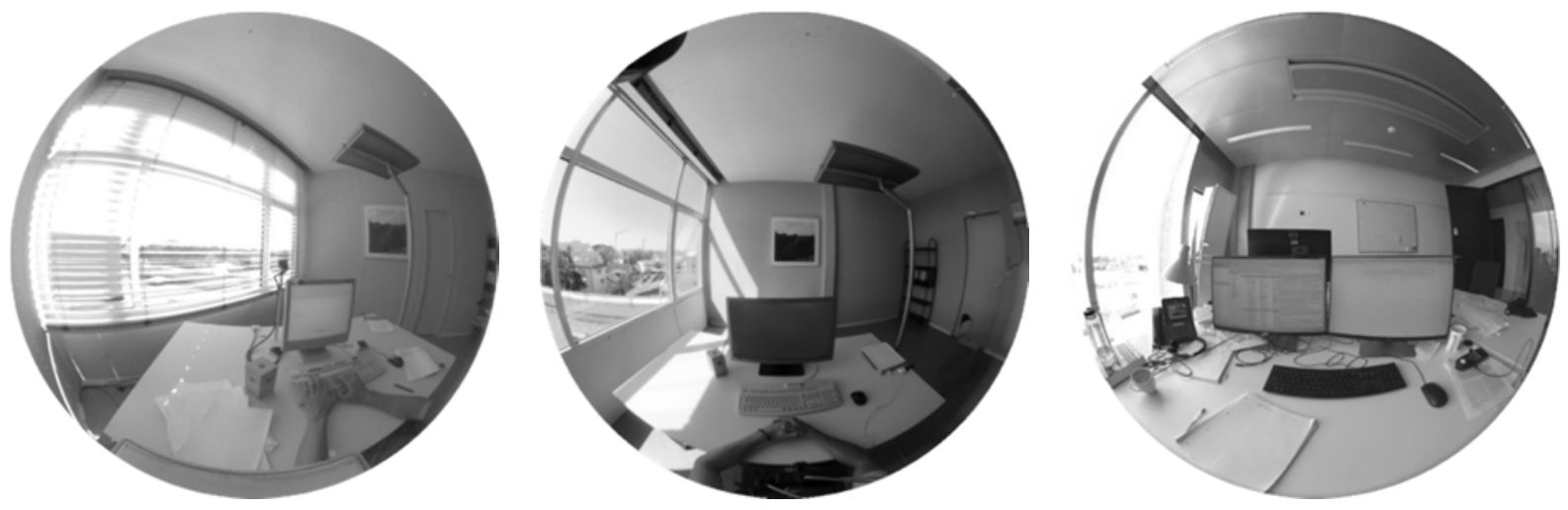

Figure 1 - Visual scenes in the first (left) and second (middle) laboratory studies, and in the field study (right)

\subsection{Selection and Metrics Evaluation}

For each study, data cleaning was applied to remove unreliable data points. For the first laboratory study and the field study, the measured $E_{v}$ and a deviation threshold of $25 \%$ were used as reliability check. $E_{v}$ was not measured in the second laboratory study. Since two highprecision HDR cameras were installed in such a way that there was a $90^{\circ}$ overlapping area between the two images, luminance maps having a deviation larger than $25 \%$ for a reference 
point compared in the two overlapping images were removed. In the end, the first and second laboratory datasets and the field dataset contained respectively 45, 95, and 94 data points, each consisting of a subjective assessment of glare and the corresponding luminance map.

The three discomfort glare metric values corresponding to each visual scene were then calculated from the luminance maps through evalglare program (versions $1.20-2.08$ ) (Wienold, 2006). Evalglare first ran an algorithm on the $180^{\circ}$ luminance maps detecting the pixels having a luminance larger than five times the average luminance of the task area to define them as the glare sources. It then determined the characteristics of these glare sources, and general lighting quantities, before calculating the discomfort glare metric values for each luminance map.

\subsection{Cut-off Values Derivation}

The previous steps led to two datasets comprising, for each data point, a subjective assessment on the 4-point glare scale and the corresponding discomfort glare metric values. The laboratory dataset contained 140 discomfort glare evaluations, and the field dataset 94 evaluations. From these datasets, the cut-off values were derived for the three borderlines of the 4-point glare scale and for the three discomfort glare metrics using diagnostic statistics, and more specifically the Receiver Operating Characteristic curve (ROC curve).

Discomfort glare models produce an outcome on a continuous scale. A cut-off value can therefore be defined on the continuous scale to act as a binary classifier system. The outcome values lower than this cut-off value are then classified as a null outcome (0), and those larger as a positive outcome (1). With a dataset containing, for each discomfort glare evaluation, the discomfort glare metric value and the subjective assessment in the form of a binary variable, a confusion matrix can be established for a specific cut-off value of the discomfort glare model. The first step consisted therefore in transforming the subjective assessment variable of the field and laboratory datasets from an ordinal variable into three binary variables, as in figure 2 .

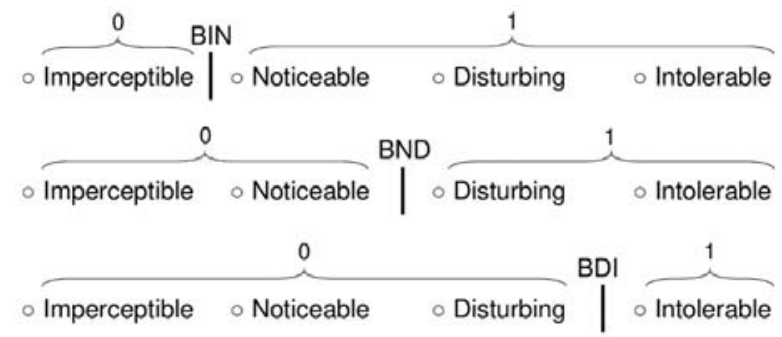

Figure 2 - Transformation of the 4-point glare scale variable into three binary variables

In theory, any value of the continuous scale of a discomfort glare model could be used as a cutoff value, and a so-called confusion matrix could be established for each of them. The True Positive Rate (TPR) and True Negative Rate (TNR) of a cut-off value can then be determined from its corresponding confusion matrix (Fawcett, 2006). Finally, the ROC curve of a discomfort glare model is a plot of the TPR and TNR of a range of cut-off values of the model (Cook, 2007) (Figure 3). The Area Under the Curve (AUC), evaluated from the ROC curve, describes the ability of the model to discriminate between two outcomes.

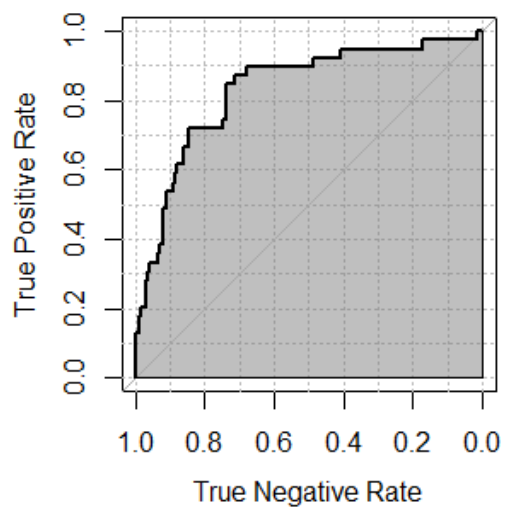

Figure 3 - Example of a ROC curve and the AUC (greyed) 
Also based on the ROC curve of the model for a specific borderline, several methods exist to define the best cut-off value, namely the one that offers the best discrimination of the discomfort glare metric values in agreement with the binary subjective assessments. For this study, three of these methods, described in (Wienold, 2019), were applied to derive the best cut-off value for each dataset, and the mean of the three results was used as the best cut-off value for a specific discomfort glare model and borderline. The three methods establish that the best cutoff value is the one that either minimises the distance from the ROC curve to the upper left corner, maximises the Youden index (Equation 3), or maximises a square fitting under the curve.

$$
\text { Youden index }=T P R+T N R-1
$$

A cut-off value was therefore determined for each dataset (laboratory + field), for each borderline (BIN + BND + BDI), and for each discomfort glare metric (DGP + $\left.E_{v}+C G I\right)$. Corresponding cut-off values were then compared between the laboratory and field datasets.

\section{Results}

The derived cut-off values are shown in table 1. As expected, a difference is observed between the laboratory and field studies. More specifically, the cut-off values derived from the field study data are systematically lower than those derived from the laboratory studies data.

Table 1 - Mean cut-off values for the two datasets, for each borderline, and for each metric

\begin{tabular}{|c|c|c|c|}
\hline Borderline & Metric & $\begin{array}{c}\text { Mean cut-off values } \\
\text { Laboratory study }(n=140)\end{array}$ & $\begin{array}{c}\text { Mean cut-off values } \\
\text { Field study }(n=94)\end{array}$ \\
\hline \multirow{3}{*}{ BIN } & DGP & 0.28 & 0.23 \\
\cline { 2 - 4 } & CGI & 27 & 19 \\
\cline { 2 - 4 } & $E_{\mathrm{v}}$ & 1903 & 836 \\
\hline \multirow{3}{*}{ BND } & DGP & 0.36 & 0.26 \\
\cline { 2 - 4 } & CGI & 29 & 26 \\
\cline { 2 - 4 } & $E_{\mathrm{v}}$ & 2949 & 1064 \\
\hline \multirow{3}{*}{ BDI } & DGP & 0.57 & 0.29 \\
\cline { 2 - 4 } & CGI & 40 & 30 \\
\cline { 2 - 4 } & $E_{\mathrm{v}}$ & 6004 & 6938 \\
\hline
\end{tabular}

The ROC curves evaluated in order to derive these cut-off values are shown in figure 5, with the colour scale representing the cut-off values. The ROC curves for the BDI borderline have been removed as they are based on very few data points in one of the two subjective assessment categories (Figure 4). There were indeed only 4 Intolerable ratings out of 140 subjective assessments in the laboratory studies, and 4 Intolerable ratings out of 94 subjective assessments in the field study. Therefore, the results for the BDI borderline should not be trusted, although they seem to support the tendency observed for the other borderlines. 


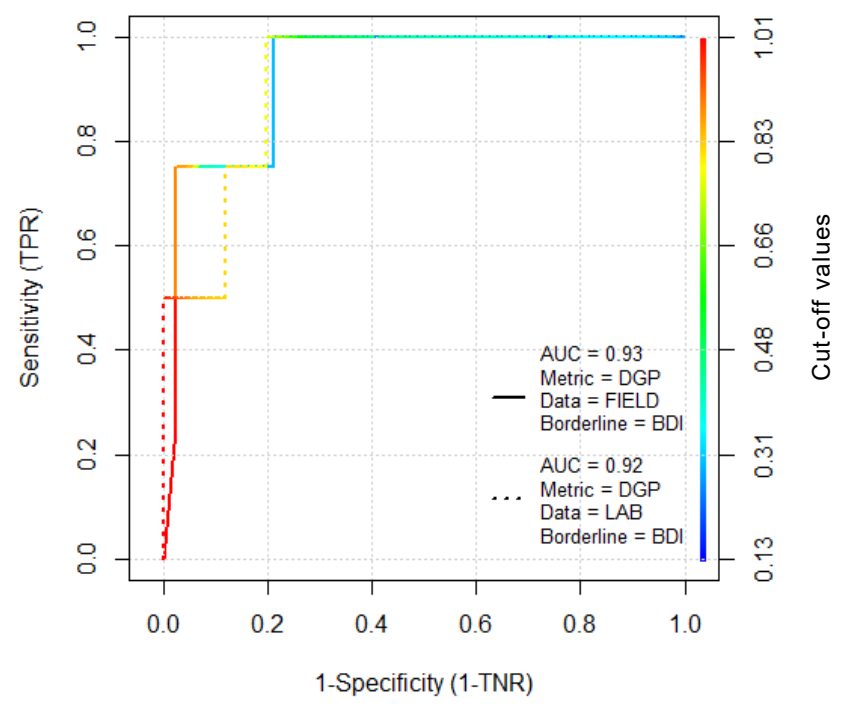

Figure $4-$ ROC curves of the two datasets, for the BDI borderline, for the DGP metric
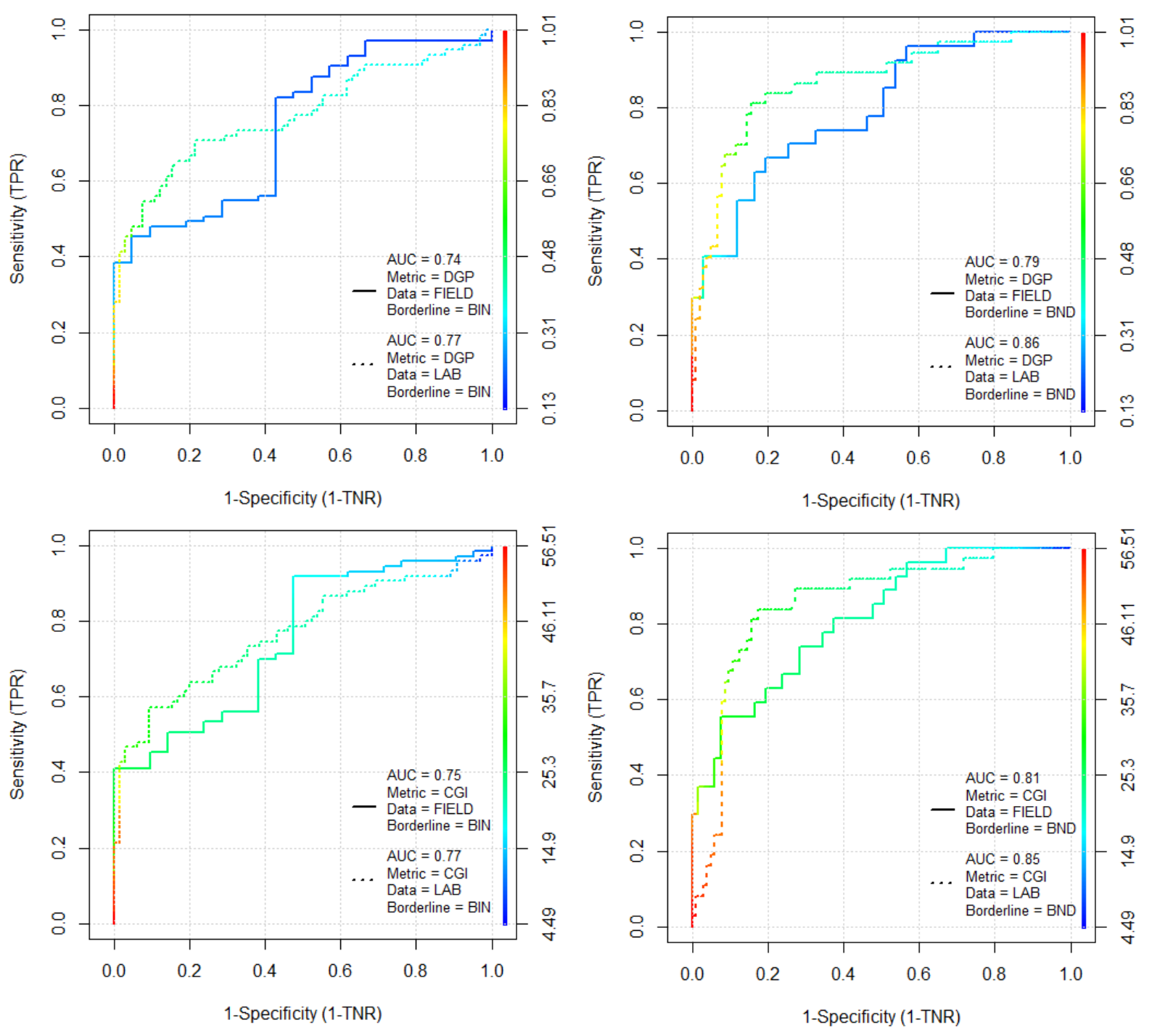

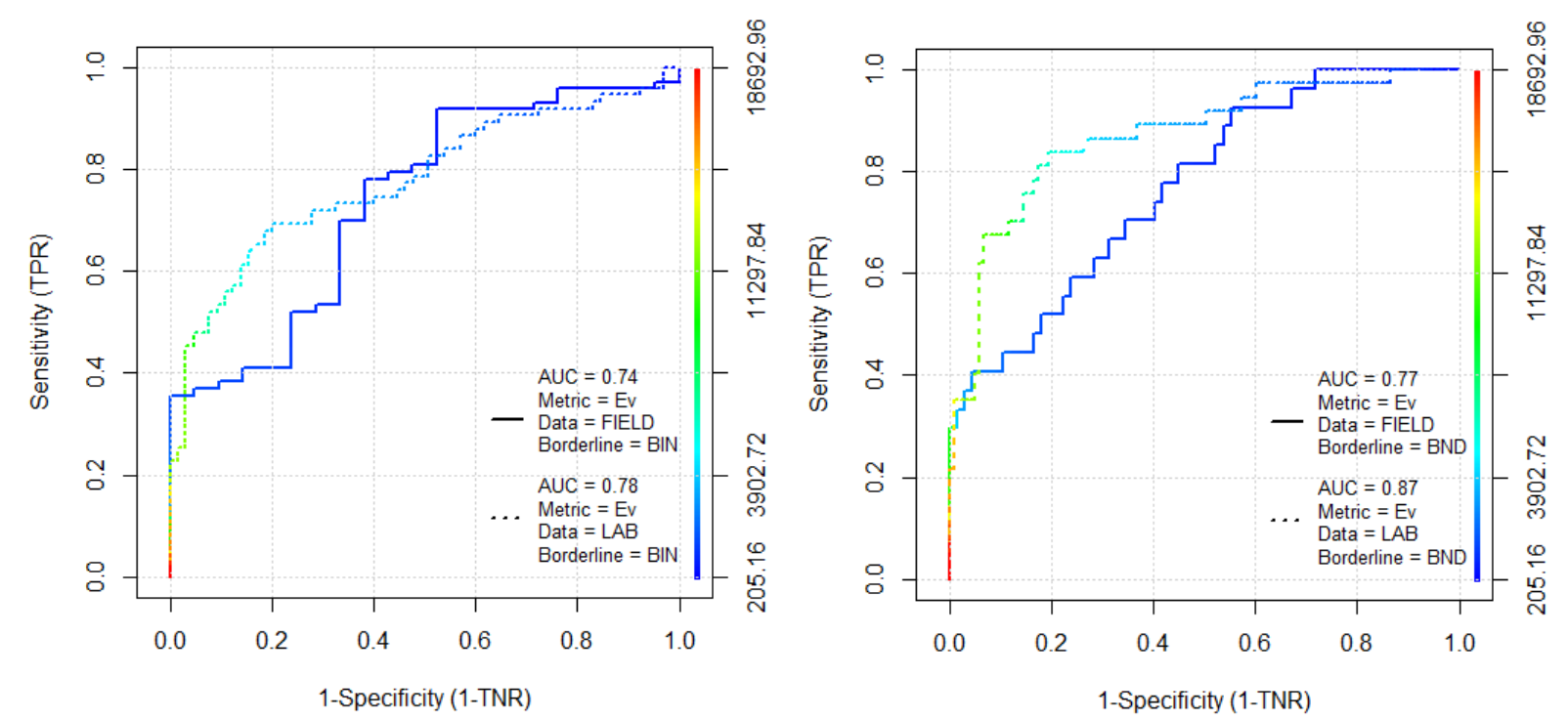

Figure 5 - ROC curves of the two datasets, for the BIN and BND borderlines, for each metric

Moreover, it can also be observed that the AUC of the ROC curves based on the field study data are lower than those based on the lab study data. This is most probably due to the noise inherent to field studies as a lot of extraneous variables can have a confounding effect, whereas these extraneous variables are better controlled in laboratory studies. Therefore, it was expected that the daylight discomfort glare models perform a bit better in the laboratory studies than in the field study.

At last, table 1 also shows that the gap between the cut-off values is so large in some cases that, for instance, the cut-off values of the BND borderline from the field study are smaller than that of the BIN borderline from the laboratory studies.

\section{Discussion}

These observations confirm what has already been highlighted in the literature, namely that discomfort glare is reported at significantly lower stimulus magnitudes in real offices than in laboratory cells, several hypotheses $(4.1-4.6)$ are put forward to try to explain it.

\subsection{Anchor bias}

When using an adjustment method to evaluate discomfort glare perception, it has been suggested that "the final setting is influenced by the initial stimulus" (Kent, 2017). It is hypothesised that this issue could also occur when using category rating scales. Different initial lighting conditions could lead to different subjective assessments of discomfort glare made for following visual scenes, with these assessments being potentially biased towards the initial conditions.

This issue could in part explain the lower cut-off values derived from the field study. As the participants were first asked to do an evaluation in the original lighting conditions, and these conditions were on average relatively dim and usually comfortable, the participants' second subjective assessment might have been biased. Since the participants noticed an increase in the brightness of the scene, they might have been tempted to change their rating towards a higher category, namely a more discomforting one, to show that they had noticed the change, although the situation was not really discomforting but just brighter.

\subsection{Difference in stimulus ranges and distributions}

Several mentions can be found in the literature where it is reported that exposure conditions in laboratory tests of indoor comfort studies are often higher than the ones experienced in most buildings (Torresin, 2018, Lamb, 2016, Chinazzo, 2018). This trend is seen in the field of daylighting as well. Table 2 compares the present lab and field studies with other published studies of the same domain regarding the vertical illuminance levels presented to the subjects. 
Table 2 - Statistics of $E_{v}$ compared between field and laboratory studies

\begin{tabular}{|c|c|c|c|c|}
\hline & Study & Mean $E_{v}$ & Median $\mathrm{E}_{\mathrm{v}}$ & Maximum $\mathrm{E}_{\mathrm{v}}$ \\
\hline \multirow{4}{*}{ 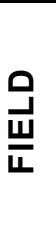 } & (Konis, 2014) & I & 905 & 1289 \\
\hline & (Hirning, 2014) & 444 & 1 & 2354 \\
\hline & (Mangkuto, 2017) & 905 & I & 2380 \\
\hline & Actual field study & 2053 & 1047 & 18496 \\
\hline \multirow{3}{*}{$\stackrel{m}{\varsigma}$} & (Wienold, 2009) & 3493 & 3010 & 11298 \\
\hline & (Konstantzos, 2016) & 2896 & 1 & 5940 \\
\hline & Actual laboratory studies & 2948 & 1847 & 9564 \\
\hline
\end{tabular}

This comparison shows that the range of vertical illuminance values experienced in real office buildings is generally lower than the range of vertical illuminance values experienced in laboratory settings. This difference is due to the fact that, in real buildings, uncomfortable conditions, such as glare, are typically avoided, whereas, in laboratory studies, researchers aim at creating a full bandwidth of situations, including uncomfortable ones.

The distribution of the lighting conditions between the two laboratory studies and the field study are therefore different, and not following a normal distribution, as shown in figure 6 .

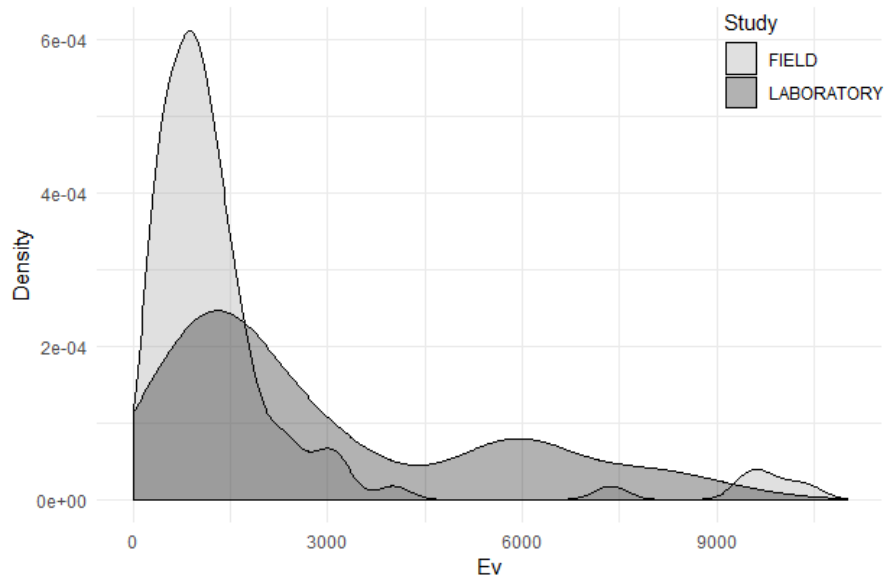

Figure 6 - Distribution of $E_{v}$ for the field and the laboratory studies

The deviations of the stimulus ranges and distributions between field and laboratory studies could have an impact on the ROC curve analysis, and in turn on the derived cut-off values, therefore biasing in part the results.

\subsection{Lighting situations experience}

The participants of each study were asked to make a point-in-time assessment of the perceived discomfort glare at the present moment when the study took place. However, in the case of the field study, the participants might, unconsciously, have taken into account past situations at their desk while doing the assessment. In the laboratory study, this experience effect would be different since the participants saw the laboratory cell for the first time when they performed the study, and they might have compared the lighting situation to their usual workplace.

Moreover, evidence from the literature suggests that participants have a tendency to recall previously encountered stimuli as lower than they really were (Fotios, 2018, LeBoeuf, 2006). Participants of the field study could have compared the present visual scene, namely the one they were asked to assess, to past situations, which they recall less discomforting. They would therefore have made a relative assessment based on this comparison, which would have been more severe than if there had been no experience at the desk and no anchors to relate to. 
Furthermore, exacerbation due to a prolonged exposure or effects of a frequent stressor can play a role in the subjective assessment made in a field study (Torresin, 2018).

\subsection{Expectations towards a familiar environment}

It is also suggested that the participants having to assess a familiar visual scene might be more critical, as they would have higher expectations for a scene that they experience every day. Therefore, the participants of a field study, who are asked to rate discomfort glare from their own office desk, might be more demanding since they are directly affected by that visual scene in their everyday life. This is not the case in a laboratory environment, since the participants know they will not have to work under these conditions in the future. The hypothesis is supported by (Torresin, 2018) mentioning that participants of a laboratory study might have lower motivation than real office workers, causing them to be more resilient to environmental stress.

\subsection{Type of participants}

The participants from the two laboratory studies came from different age groups, with some being students and others being office workers, whereas the participants of the field study were all office workers. Attitudes, tolerance and expectations could have influenced the subjective assessment (Lamb, 2016). A deeper look into the background and age differences between the participants of the two types of studies can lead to more clues to explain the obtained results.

\subsection{Context}

Another hypothesis to explain the lower cut-off values observed in field studies might be linked to the context in which the subjective assessment is collected. First, a participant could feel different, e.g. more relaxed or curious, in a laboratory environment than in their usual working environment. Moreover, environmental factors, such as the view through the window, might be more appealing or dissatisfactory in an unknown environment than the view to which a participant is accustomed. Finally, confounding variables related to the physical environment, such as temperature or air quality, might also play a role, as these are not controlled in field studies. All these factors might lead the participant to be more tolerant towards discomfort glare in a laboratory environment than in their usual work environment.

\section{Conclusion}

Cut-off values were derived from data of a field study $(n=94)$ and two laboratory studies $(n=$ 140 ), having similar protocols, but acquired in different environments. The cut-off values were evaluated through ROC curve analyses using the collected discomfort glare evaluations, i.e. subjective assessments of discomfort glare stimuli on a 4-point glare scale and corresponding discomfort glare metric values calculated from measured luminance maps. By comparing the cut-off values derived from the field and laboratory studies, we observed that discomfort glare is reported for lower stimulus magnitudes in the field study. This observation was expected, since a same trend could be highlighted in the literature. Several hypotheses are brought up to explain this observation. First, it is assumed that participants generally do relative assessments, and not absolute ones as they are usually interpreted. Participants tend to rate a stimulus, for instance discomfort glare, by comparing it to some anchor point, as might be the case in the field study. Another comparative point might be related to the participant's memory of similar situations, which explains the bias brought by the lighting situations experience for instance. Moreover, it is also suggested that the type of the participants might have an influence on the subjective assessments. At last, the context in which the evaluations are made might also bias the data. On the one hand, participants surveyed at their own desk might have higher motivations or expectations, and on the other hand, they might also be more stressed out because they are surrounded by their working environment, making them more severe in their subjective assessment. The stimulus ranges and distributions might also play a role in biasing the results. Finally, confounding variables related to the environment, such as the view through the window or the temperature, could also have an influence on the subjective assessment of discomfort glare.

To better understand the potential effects of these hypotheses, it is highly recommended that future studies look deeper into this topic, and offer solid experimental evidence. For instance, 
field studies could be conducted in offices building where desk occupancy is flexible, i.e. flex desk, to attenuate bias related to expectations or experience at the participants' own desks. Laboratory studies in which participants are recruited amongst real office workers, and with a range of stimuli similar to those that are found in the field could also be conducted to investigate the bias related to the type of participants and to different stimulus distributions. At last, the participant's stress level while taking part in a study and her/his satisfaction at work should be recorded and analysed simultaneously to detect any confounding effect.

\section{References}

CHAUVEL, P., COLLINS, J., DOGNIAUX, R. \& LONGMORE, J. 1982. Glare from windows: current views of the problem. Lighting Research \& Technology, 14, 31-46.

CHINAZZO, G., PASTORE, L., WIENOLD, J. \& ANDERSEN, M. 2018. A field study investigation on the influence of light level on subjective thermal perception in different seasons. Windsor Conference: Rethinking comfort. Windsor, UK.

COOK, N. 2007. Use and Misuse of the Receiver Operating Characteristic Curve in Risk Prediction. Circulation, 928-935. (DOI: 10.1161/CIRCULATIONAHA.106.672402)

EINHORN, H. 1979. Discomfort glare: a formula to bridge differences. Lighting Research \& Technology, 11, 90-94.

ERELL, E., KAFTAN, E. \& GARB, Y. 2014. Daylighting for Visual Comfort and Energy Conservation in Offices in Sunny Regions. 30th PLEA International Conference - Sustainable Habitat for Developing Societies. Ahmedabad, India.

FAWCETT, T. 2006. An introduction to ROC analysis. Pattern Recognition Letters, 27, 861-874.

FISEKIS, K., DAVIES, M., KOLOKOTRONI, M. \& LANGFORD, P. 2003. Prediction of discomfort glare from windows. Lighting Research \& Technology, 35, 360-371.

FOTIOS, S. 2018. Using Category Rating to Evaluate the Lit Environment: Is a Meaningful Opinion Captured? The Journal of the Illuminating Engineering Society, 1-17.

HIRNING, M., ISOARDI, G. \& COWLING, I. 2014. Discomfort glare in open plan green buildings. Energy and Buildings, 70, 427-440.

HOPKINSON, R. 1963. Architectural Physics: Lighting, London, UK: HMSO.

KENT, M., FOTIOS, S. \& ALTOMONTE, S. 2017. Discomfort glare evaluation: The influence of anchor bias in luminance adjustments. Lighting Research \& Technology.

KONIS, K. 2014. Predicting visual comfort in side-lit open-plan core zones: Results of a field study pairing high dynamic range images with subjective responses. Energy and Buildings, 77, 6779.

KONSTANTZOS, I. \& TZEMPELIKOS, A. 2016. Daylight glare evaluation with the sun in the field of view through window shades. Building and Environment.

KUHN, T., WIENOLD, J. \& MOOSMANN, C. 2013. Daylight glare : Age effects and their impact on glare evaluation. 8th Energy Forum on Solar Building Skins. Bressanone, Italy. (DOI:

LAMB, S. \& KWOK, K. 2016. A longitudinal investigation of work environment stressors on the performance and wellbeing of office workers. Applied Ergonomics, 52, 104-111.

LEBOEUF, R. \& SHAFIR, E. 2006. The long and short of it: physical anchoring effects. Journal of Behavioral Decision Making, 19, 393-406.

MANGKUTO, R., KURNIA, K., AZIZAH, D., ATMODIPOERO, R. \& SOELAMI, F. 2017. Determination of discomfort glare criteria for daylit space in Indonesia. Solar Energy, 149, 151-163.

MOOSMANN, C., WIENOLD, J., WAGNER, A. \& WITTWER, V. 2012. Ermittlung relevanter Einflussgrößen auf die subjektive Bewertung von Tageslicht zur Bewertung des visuellen Komforts in Büroräumen. Abschlussbericht.

OSTERHAUS, W. 2004. Discomfort glare assessment and prevention for daylight applications in office environments. Solar Energy, 79, 140-158. 
OSTERHAUS, W. \& BAILEY, I. 1992. Large Area Glare Sources and Their Effect on Discomfort and Visual Performance at Computer Workstations. 1992 IEEE Industry Applications Society Annual Meeting. Houston, USA.

PAINTER, B., FAN, D. \& MARDALJEVIC, J. 2009. Evidence-based daylight research: development of a new visual comfort monitoring method. Lux Europa, 11th International Lighting Conference. Istanbul, Turkey.

PIERSON, C., PIDERIT, M., WIENOLD, J. \& BODART, M. 2017. Discomfort glare from daylighting: influence of culture on discomfort glare perception. CIE 2017 Midterm Meeting. Jeju, South Korea.

PIERSON, C., WIENOLD, J. \& BODART, M. 2018. Review of Factors Influencing Discomfort Glare Perception from Daylight. The Journal of the Illuminating Engineering Society, 14, 111-148.

REINHART, C. \& WIENOLD, J. 2011. The daylighting dashboard - A simulation-based design analysis for daylit spaces. Building and Environment, 386-396.

SAREY KHANIE, M., STOLL, J., EINHÄUSER, W., WIENOLD, J. \& ANDERSEN, M. 2017. Gaze and discomfort glare, Part 1: Development of a gaze-driven photometry. Lighting Research \& Technology, 49, 845-865.

TOKURA, M., IWATA, T. \& SHUKUYA, M. 1996. Experimental study on discomfort glare caused by windows: Development of a method for evaluating discomfort glare from a large light source. Journal of Architecture, Planning and Environmental Engineering, 17-25.

TORRESIN, S., PERNIGOTTO, G., CAPPELLETTI, F. \& GASPARELLA, A. 2018. Combined effects of environmental factors on human perception and objective performance: a review of experimental laboratory works. Indoor Air.

VELDS, M. 2000. Assessment of lighting quality in office rooms with daylighting systems. PhD dissertation, Technische Universiteit Delft (TUD).

WIENOLD, J. 2009. Daylight Glare in Offices. PhD dissertation, Universität Karlsruhe (TH).

WIENOLD, J. \& CHRISTOFFERSEN, J. 2006. Evaluation methods and development of a new glare prediction model for daylight environments with the use of CCD cameras. Energy and Buildings, $38,743-757$.

WIENOLD, J., IWATA, T., SAREY KHANIE, M., ERELL, E., KRAFTAN, E., RODRIGUEZ, R., GARRETON, J. A., TZEMPELIKOS, T., KONSTANTZOS, I., CHRISTOFFERSEN, J., KUHN, T. E., PIERSON, C. \& ANDERSEN, M. 2019. Cross-validation and robustness of daylight glare metrics. Lighting Research \& Technology.

YAMIN GARRETÓN, J., COLOMBO, E. \& PATTINI, A. 2018. A Global Evaluation of Discomfort Glare Metrics in Real Office Spaces with Presence of Direct Sunlight. Energy and Buildings.

YAMIN GARRETÓN, J., RODRIGUEZ, R., RUIZ, A. \& PATTINI, A. 2014. Degree of eye opening: A new discomfort glare indicator. Building and Environment, 88, 142-150. 